\title{
Correction to: The World Color Survey: Data Analysis and Simulations
}

Peter Lewinski, Michal Lukasik, Konrad Kurdej, Filip Leonarski, Natalia Bielczyk, Franciszek Rakowski and Dariusz Plewczynski

\section{Correction to:}

Chapter 16 in: À. Massip-Bonet et al. (eds.), Complexity Applications in Language and Communication Sciences, https://doi.org/10.1007/978-3-030-04598-2_16

In the original version of the book, the belated correction from author to remove the co-author name "Joanna Raczaszek-Leonradii" from Chapter 16 should be incorporated. The correction chapter and the book have been updated with the change. 